\title{
Geoelectric Upper Mantle Anomalies in the United States
}

\author{
T. MADDEN \\ Department of Earth and Planetary Sciences \\ Massachusetts Institute of Technology, Cambridge \\ (Received January 12, 1970)
}

\begin{abstract}
Geoelectric studies have shown that a pronounced high conductivity region exists in the upper mantle of the Southwestern United States. This anomaly is well correlated with other geophysical anomalies. Tne electrical measurements can be interpreted to give upper mantle temperatures very close to the melting point. Preliminary measurements near tne California ocean-continent boundary indicate even higher conductivities exist in the mantle under the ocean.
\end{abstract}

Magnetic variation and magnetotelluric studies have delineated significant geoelctric anomalies in the Western United States. This area is part of the Cordilleran system, and in the southern part includes the Rocky Mountains, the Colorado plateau, the Basin and Range province, the Sierra Nevada Mountains, and the Pacific Border province. The region has a long tectonic history but is still active. It is of special interest to students of modern global tectonics as it represents a region where an oceanic ridge system, the East Pacific Rise, has merged with a continent. This region and its extension north into Canada and Alaska also forms a break in the Circum-pacific belt of deep focus earthquakes.

The southern and central section of the Cordilleran region in the United States has been extensively studied geophysically and shows many anomalous properties. The region is characterized by low gravity values (Woollard, 1966), smooth magnetic profiles (Pakister and Zietz, 1965), high heat flows (Warren, et al, 1969), and low seismic velocities (Herrin and Haggert, 1962) as well as high electrical conductivites. All of these properties can be qualitatively explained by assuming anomalously high temperatures in the upper mantle.

A crude representation of typical geoelectric results in relation to the major physiogxaphic provinces in the Western United States ts shown in figure 1. The first extensive deep electrical studies in this region were magnetic variation measurements made by Schmucker (Schmucker, 1964) across California, Arizona, and New Mexico in the Basin and Range Province but south of the Colorado Plateau. These studies showed a distinct difference between the upper mantle electrical conductivity of the Basin and Range province and that of the Great Plains to the east. A rise of isoconductivity surfaces within the upper mantle of 100 kilometers in the Basin and Range province with a more localized rise of 150 kilometers near the Rio Grande Valley, is postulated to explain the obser vations. 
Magnetic Variation and Magnetotelluric Studies in Western United States

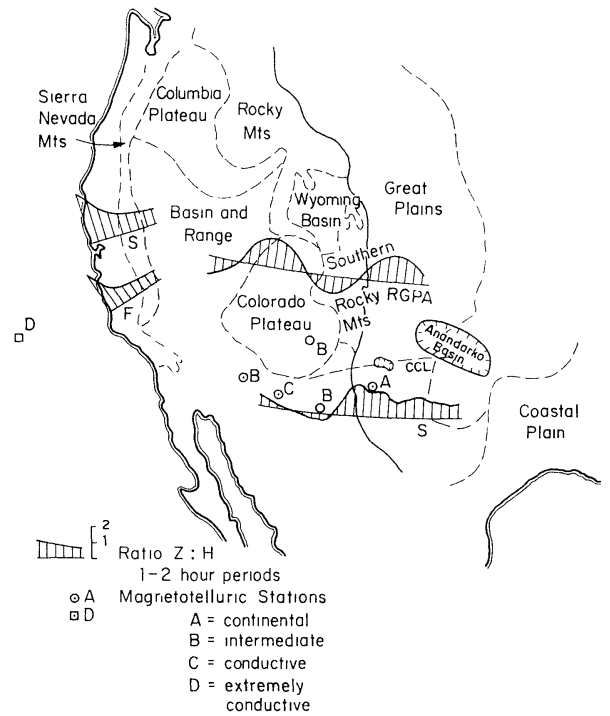

Fig. 1 : Physiographic Provinces and Typical Magnetic Variation and Magnetotelluric Results in Western United States RGPA-median magnetic variation from Reitzel, Gough, Porath and Anderson (1969) internal $Z$ in phase : $H$ east CCL-magnetic variation profile from Caner, Cannon and Livingston (1967)

S-magnetic variation profiles from Schmucker (1964) $Z$ in phase : $H$ normal to strike direction

$\mathrm{F}$-magnetic variation profile from Filloux (1967) $|Z|: H$ normal to coast line

- ocean bottom magnetotelluric station from Filloux (1967)

- -magnetotelluric stations from Swift (1967)

These observations have been extended to the north by Gough, Reitzel, Porath and Anderson using large two dimensional arrays of magnetic variometers. (Gough and Reitzel, 1967; Reitzel, et al, 1969) Their studies also show an anomaly at the edge of the Great Plains, but a second feature is observed at the boundary between the Colorado Plateau and the Basin and Range Province to the west. They explain their observations by a localized rise of isoconductivity surfaces of some 150 kilometers under the Southern Rocky Mountains, a localized rise of some 200 kilometers under the Wasatch Front and a regional rise of some 100 kilometers in the Basin and Range province. This model leaves most of the Colorado plateau with a typical continental mantle electrical conductivity profile.

Further corroborating studies were made by Swift (Swift, 1967), who conducted a series of magnetotelluric measurements in the vicinity of Schmucker's profile. His interpretations also show a rise of isoconductivity surfaces under the Basin and Range province of 100 to 150 kilometers.

Caner, Cannon and Livingston (Caner et al, 1967) ran a magnetic variation profile across New Mexico, Northwest Texas and into Oklahoma. They indicate that the high conductivity anomaly does not stop at the boundary of the Great plains but extends much further east in the region of their profile. Their profile, however, crossed near the Tucumcari and Anandarko Basins and it is very possible that sedimentary features accounted for their observations.

Other electrical measurements have been made in these regions using resistivity and magnetotelluric methods, but they have involved spacings too short or frequencies too high to determine clearly the upper mantle properties (Keller, et al, 1966; Cantwell, et al, 1965). 
The anomalous mantle electrical conductivity values inferred by the magnetic variation and magnetotelluric studies can be explained by either an increase of mantle temperature, or by an increase of the iron content of the mantle rocks. Assuming the effect is due only to temperature, one can use Ringwood's pyrolite petrological model aud laboratory measurements on the temperature dependence of the electrical conductivity of pyrolite constituents to infer the mantle temperatures from the electrical conductivity estimates. This procedure gives temperature estimates for the upper mantle in the anomalous regions up to $600^{\circ} \mathrm{C}$ higher than the normally postulated continental temperature distribution (Swift, 1967). Such temperatures should bring the mantle rocks to their melting point (Ringwood, 1966). Because of the strong dependence of conductivity on the iron content (Hamilton, 1965), the electrical measurements cannot uniquely determine the temperature, but some corroborating evidence is provided by the seismic data. Toksöz has pointed out that the travel time delays of seismic signals in this region, relative to the mid-continent region, are characteristic of transmission through a zone of partially melted rocks (Toksöz, et al, 1969). The $p$ waves are delayed 1 to 2 seconds relative to the midcontinent, while the $S$ waves are delayed 4 to 8 seconds (Cleary and Hales, 1966; Doyle and Hales, 1967). For rocks not too close to their melting point this ratio should be close to $1: 2$ rather than the $1: 4$ ratio observed. The heat flow evidence also supports the hypothesis that the electrical anomalies are essentially due to temperature anomalies (Warren, et al, 1969). The thickness of the anomalous zone cannot be determined from the present electrical measurements, as the increased conductivity reduces the depth of penetration of the electric currents. In this region the 24-hour-period signals, which were the lowest frequency used, do not sense much deeper than 200 or 300 kilometers into the mantle.

The geographic coverage of electrical measurements is still quite sparse in this region. This is especially true in the northern section so that it is not known at present how the geoelectric anomalies of the United States Cordilleran tie in with those of the Canadian Cordilleran.

Other magnetic variation observations have been made to study the edgeeffect of the ocean-continent boundary in California. This work was initiated by Schmucker (Schmucker, 1964), and extended by Cox and Filloux (Filloux, 1967). Filloux also obtained telluric recordings on the edge and bottom of the continental shelf and a magnetotelluric sounding on the ocean bottom $630 \mathrm{~km}$ off shore. His telluric measurements show that the electric currents in the ocean cannot account for the magnetic variation anomaly on the shore and thus the oceanic mantle must produce an anomalous effect. The low telluric field values also lead to a conductive oceanic mantle interpretation of the magnetotelluric observations. The independently interpreted magnetic variation and magnetotelluric measurements give similar estimates of oceanic mantle conductivities. These conductivities are very high at very shallow depths. In fact Filloux's estimate of $0.5 \mathrm{mhos} / \mathrm{meter}$ at 30 kilometers depth is an order of magnitude higher than the estimated continental mantle conductivities at depths of 200 to 300 kilometers even in the anomalous areas. Oceanic mantles are assumed to be hotter than continental mantles because of a deeper 
distribution of radioactive elements. This should raise the isotherms about 100 kilometers (Ringwood, 1966). Filloux's oceanic mantle conductivity estimates, however, are too high and occur at too shallow a depth to be explained as a temperature effect. If these results are not a local phenomenon one would have to assume that a very different mineralogic composition exists in the oceanic mantle. Filloux favors a tholeitic basalt composition. More oceanic measurements are needed to clarify this picture.

Electrical measurements have also been made in other sections of the United States, but at present no systematic geoelectric anomalies due to mantle electrical properties are known outside of the Cordilleran region. More measurements and more quantitative interpretations are needed in the Cordilleran before one can fully understand this unusual portion of the mantle.

\section{Acknowledgements}

The author wishes to thank Mr. I. Zeitz of the United States Geologic Survey and Dr. $\mathrm{H}$. Porath at the University of Texas for providing him with recent unpublished results from their respective groups. He is indebted to Professor Cox for the clarification of certain features of oceanic edge effects. He has also benefited from discussions of the geophysical and geochemical significance of the geoelectric data with Dr. C.M. Swift and Professor N. Toksöz. The author's work in geoelectricity has been sponsored by the Office of Naval Research under Nonr 1841 (75), the Petroleum Research Fund and the National Science Foundation, and he gratefully acknowledges their support.

\section{References :}

Caner, B., W.H. Canon and C.E. Livingston, Geomagnetic depth ounding and upper mantle structures in the Cordilleran Region of Western North America, J. Geophys. Res., 72, 6335-6351, 1967.

Cantwell, T., P. Nelson, J. Webb and A.S. Orange, Deep resistivity measurements in the pacific Northwest, J. Geophys. 70, Res., 1931-1938, 1965.

Cantwell, T. and A. Orange, Further deep resistivity measurements in the Pacific Northwest, J. Geophs. Res., 70, 4068-4072, 1965.

Cleary, J. and A.L. Hales, An analysis of the travel times of $\mathrm{P}$ waves to North American stations, in the distance range of $32^{\circ}$ to $100^{\circ}$, Bull. Seis. Soc. Am., 56, 467-489, 1966.

Cox, C. S., J.H. Filloux and J.C. Larsen, Electromagnetic studies of ocean currents and electrical conductivity below the oceanfloor, in Vol. IV, Part I of The Sea, A.E. Maxwell, ed., John Wiley and Sons (in proof).

Doyle, H.A. and A.L. Hales, An analysis of the travel times of $\mathrm{S}$ waves to North American stations in the distance range $28^{\circ}$ to $82^{\circ}$, Bull. Seism. Soc. Am., 57, 761-771, 1967.

Filloux, J. H., Oceanic electric currents, geomagnetic variations and deep electrical conductivity strucure of the ocean continent transition of Central California, $\mathrm{Ph}$. D. Thesis, University of California, San Diego, 1967.

Gough, D.I. and J.S. Reitzel, A portable three--component magnetic variometer, J. Geomag. and Geoelect., 19, 203-215, 1967.

Hamilton, R.M., Temperature, variation at coostant pressure of the electrical conductivity of periclase and olivine, J. Geophys. Res., 70, 5679-5692, 1965.

Keller, G.V., L.A. Anderson and J.I. Pritchard, Geological Survey investigations of the electrical pro- 
perties of the crust and udder mantle, Geophs., 31, 1123-1144, 1966.

Herrin, E. and J. Taggart, Regional variations in Pn velocity and their effect on the location of epicenters, Bull. Seis. Soc. Am, 52, 1037-1046, 1962.

Pakister, L.C. and I. Zeitz, Transcontinental and upper mantle structure, Rev. Geophys., 3, 505-520, 1965.

Reitzel, J.S., D.I. Gough, H. Porath and C.W. Anderson III, Geomagnetic depth sounding and upper mantle structure in the Western united States, (preprint) contribution no. 103, Geosciences Division, Southwest Center for Advanced Studies, 1969.

Ringwood, A.E., Mineralogy of the mantle, in Advances in Earth Sciences, ed. by P. Hurley, M.I.T. Press, Cambridge, 357-399, 1966.

Schmucker, U., Anomalies of geomagnetic variations inthe Southwestern United States, J. Geomag, and Geoelect., 15, 193-221, 1964.

Swift, C.M. Jr., A magnetotelluric investigation of an electrical conuctivity anomaly in the Southwestern United States, Ph. D. Thesis, Massachusetts Institute of Technology, 1967.

Toksöz, N.M., S.C. Solomon and H.E. Kehrer, Geophysical data and upper mantle properties under North America, in preparation, 1969.

Warren, R.E., J.C. Slater, V. Vacquier and R.F. Roy, A comparison of terrestrial heat flow and transient geomagnetic fluctuations in the Southwestern United States, Geophys., 34, 463-478, 1969.

Wollard, G.P., Regional isostatic relations in the United States, in The Earth Beneath the Continents, edited by J.S. Steinhart and T. Jefferson Smith, Geophys. Monograph, 10, Am. Geophys. Union, 557594,1966 